diligently continued for upwards of two hours. Brandy-toddy was liberally and firequently administered, alternated with doses of a weak infusion of the secale cornutum. Cold water was occasionally dashed over the face, and bottles of hot water constantly kept at the feet. For nearly an hour an occasional gush of blood was discharged, and at times Mrs. A. seemed as if she was about to expire. The gushes, however, became less fiequent and smaller in quantity ; and as the restorative and precautionary measures were rigoronsly enforced for some hours, I had the satisfaction, before 1 felt it safe to leave her, of hearing her say that she felt "very comfortable." Her after-recovery was highly satisfactory.

Mrs. A., aged 49, is the mother of twelve children, and all alive. I have attended her in her six last confinements, all of which were unusually protracted and painful. As the catamenia had left her for some months, she was in the belief that a change was going on, when she was one evening suddenly seized with pain in the back, accompanied with a discharge of a sanguineous nature, which took place ten days or so before her severe illness; she had seen more or less of it every day up to the timo 1 was sent for. In this case there was no abdominal distension, and no mammary enlargement. Though I have bcen in extensive obstetric practice for the last seventeen years, having attended near two thousand cases, 1 have only met with three cases of this description. Obstetric authors do not seem to have metwith many such cases, if one may judge from the summary and careless way in which they have been noticed.-Edin. Monthly Jour. of Med. Science.

\title{
A CASE OF SENILE GANGRENE OF THE INFERIOR EXTREMITIES.
}

BY ROBERT CAMPBEJL, M.D., ASSISTANT DHMONSTRATOR IN THE MEDICAL COLIEGE OF GEORGIA.

The rareness in our region of this disease, will perhaps invest the subjoined case with some interest :-

E. C., aged about 50 years; of spare habit and florid complexion; carriage-maker by trade-ivas brought from Anderson C. H., S. C., and admitted into the Augusta Hospital on the 11th May last. I saw him at 4, P. M., in consultation with Prof. Jos. A Eve, the attending physician. Found the whole of the right and the anterior third and heel of the left foot, perfectly black, without sensation or sensibility, with vesications studding their upper surface, and yielding the peculiar" mortification odor ;" indeed, these parts were in a completely sphacelated condition. He complained, when the extremities were handled, of pain only about the ankle-joints; the legs were œdematous almost to the knee-joints-pitting on pressure. Extremities cold and dry; pulse small, unresisting, and 150 in frequency; tongue coated with thick, yellow fur; appetite deficient; mental faculties somewhat impaired.

All we could gather concerning the history of the case was, that a short time prior to this he had gotten his foot very wet in a rain, having to travel some distance in the railroad car, and not being able to change 
his boots, suffered extremely with swelling and a burning sensation in the feet. He had been a man of intemperate habits, and had, at a former time, lost several of the toes of the left foot from a previous attack of mortification.

Diagnosis.-Mortification by ossification of the arteries.

Prognosis. - Of course, very unfavorable.

Treatment.-Amputation presented to our minds the only possible hope of staying the dilapidation so fast ensuing. Hence the immediate removal of the right.(the worst) leg was determined upon; and at 6 o'clock, I amputated the leg by the circular operation at about the junction of the upper with the middle third-the patient under chloroform. The arteries opposed a considerable resistance to the knife, the passage of which conveyed an unusual grating sensation, as from collision with petrified rather than ossified vessels. Their ligation was effected with more than usual facility, inasinuch as they protruded beyond the contracted surrounding tissues, instead of retracting within them.

We left the patient comfortable, having lost very little blood, and experienced no pain during the operation; nor would he be convinced of its execution until his attention was directed to the absence of the limb. R. Port wine, $\int \xi i j$; ; quinine, grs. v. To be repeated every six hours. Diet-chicken soup, freely administered.

12th.-Patient under the influence of quinine; complains of some pain in the stupnp; extremities still cold; pulse rather more resisting, and only 100 in frequency; will take but little nourishment. R. Continue wine every three hours, and quinine three times a-day, in doses as before. Enemata to relieve the bowels ; and should pain continue, laudanum 30 gtts., repeated pre-re-nata. Left foot treated with cloths saturared with the chloride of soda.

13th.-Much weaker; extremities of still lower temperature; pulse very feeble and intermittent; delirium complete.

\title{
14th.-Died at 7, A. M.
}

It would have been an interesting investigation to have ascertained to what extent the aterial system had been subjected to this ossific deposition. This I intended to have accomplished, had not my own indisposition at the time prevented. But the perfect character of the ossification at the point examined, the slight effect of the stinulus, and the apparent absence of any recuperative energy in the constitution of the patient, notwithstanding so large a proportion of the contaminating mass had been removed, and without the loss of blood or the shock of pain -are circumstances which seem to indicate the circulatory apparatus to have been much embarrassed in its functions, from the extensive pervasion of the disease.- Southern Med. and Surg. Journal.

\section{THE BOSTON MEDICAL AND SURGICAL JOURNAL.}

\author{
BOSTON, A G UST 27, 1851 .
}

Water in Surgery.-Dr. Hamilton's Translation from the French, of Amussat's Treatise on the Employment of Water in Surgery, makes an 